\title{
Adherence to Vaccine Requirements among Hajj Pilgrims in Saudi Arabia, 2017-2019
}

\section{${ }^{\star}$ Adel Fahad Alotaibi ${ }^{1}$, Sami S Almudarra², Homoud S Algarni ${ }^{3}$, Yasser Bakhsh $^{3}$, Zahir Mohamed Elamin Dafaalla ${ }^{3}$, Nada Abdulaziz Alhowail ${ }^{3}$, Abdulla M Assiri²}

${ }^{1}$ Department of FETP, King Saud University, Riyadh, Saudi Arabia. ${ }^{2}$ Public Health Agency, Ministry of Health, Saudi Arabia. IInternational Health Regulation Program, Ministry of Health, Saudi Arabia. *Email: alotaibiadel18@gmail.com

\begin{abstract}
Hajj pilgrims must have certain vaccines for pilgrimage; these requirements aim to reduce the spread of infectious diseases. This study analyzed the trends in vaccine adherence for meningitis, yellow fever, and polio from January 2017December 2019. These trends can help in guiding future policymaking to prevent outbreaks during Hajj and similar mass gatherings. We analyzed data using descriptive statistics for Hajj pilgrims and Hajj seasonal workers arriving in Saudi Arabia over three years (2017-2019). Health Control Centers (HCCs) collected data at points-of-entry (PoE) and entered it into Saudi Arabia's Health Electronic Surveillance Network (HESN). We reviewed HESN data to collect information on total passengers arriving per country and the number of passengers vaccinated for: meningococcal meningitis, poliomyelitis, and yellow fever. We compared data to identify the difference in vaccination by region. We used chi-square tests to assess differences in compliance rate among these travelers by year and country of origin. The number of participating countries increased from 113 to 132 . Meningitis vaccine coverage increased by 5\% from 2017-2019. The increase was not statistically significant. Asia had the lowest overall adherence rate (83\%). Yellow fever adherence decreased significantly using a difference of mean adherence between 2017 and 2019 ( $p$-value 0.01). Polio vaccination adherence decreased by 5\% from 2017 to 2019; this was not significant ( $p$-value $=0.08$ ). The vaccine coverage increased for meningitis and decreased for yellow fever and polio. Less than $100 \%$ vaccine adherence among Hajj travelers creates the potential for the spread of infectious diseases. Proof of vaccination should be required in submitted visa applications. Countries of origin and Saudi Arabia must work together to ensure that all Hajjis are adequately vaccinated before departure.
\end{abstract}

Keywords: Hajj; meningitis; yellow fever; polio; vaccination

\section{INTRODUCTION}

In 2005, the World Health Organization (WHO) created the International Health Regulations (IHR). IHR is an agreement between 196 countries, also called State Parties, that aims to prevent global outbreaks and ensure efficient response to public health hazards by implementing and applying various public health activities, including preparation, alert, and response ${ }^{1}$. The Kingdom of Saudi Arabia joined the state parties of IHR on the $15^{\text {th }}$ of June $2007^{2}$.

Corresponding Author: Adel Fahad Alotaibi

Department of FETP, King Saud University, Riyadh, Saudi Arabia

*Email: alotaibiadel18@gmail.com 
Hajj is one of the largest mass gatherings in the world. Hajj season is based on the Islamic calendar and occurs during the $8^{\text {th }}-13^{\text {th }}$ of Dhul-Hijah. The number of pilgrims who can perform Hajj is based on a ratio of 1 pilgrim/1000 Muslims in a particular country ${ }^{3}$. Typically, around 2 million pilgrims and 50,000 seasonal workers from more than 183 countries come in close contact during Hajj ${ }^{4}$.Shared living spaces, communal meal preparation, and various Hajj activities, such as barefoot walking, dense crowds often in extreme temperatures $\left(45^{\circ} \mathrm{C}\right.$ in summer), shared toilet facilities and razors, etc., can increase the risk of infectious disease during Hajj ${ }^{5}$. Common respiratory infections, meningococcal disease, poliomyelitis, hepatitis $A, B$, and $C$, gastroenteritis, and other various zoonotic infections pose serious public health threats to Hajj pilgrim 6-8.

Saudi Arabia's Ministry of Health $(\mathrm{MOH})$ annually revisits health requirements for Hajj pilgrims in coordination with international health authorities. This allows them to design and implement policies for preventing the spread of pathogens at Hajj and respond to emerging international outbreaks ${ }^{9}$. The $\mathrm{MOH}$ issues an updated list of required and recommended vaccines for pilgrims ${ }^{10}$.

Hajj-related meningococcal disease outbreaks have been reported. In 1987, an outbreak was caused by Neisseria meningitides serogroup A and Serogroup W135. A 2000 outbreak caused by $N$. meningitides serogroup W13511,12. According to Al-Tawfiq and Memish et al., 3.4\% of pilgrims arriving for Hajj were carriers of $N$. meningitides. Vaccines against bivalent $A$ and $C$ meningococcal were made mandatory for pilgrims after the 1987 outbreak $^{13}$.

All Hajj pilgrims and seasonal workers are required to be vaccinated for meningococcal meningitis ${ }^{14}$. Poliomyelitis and yellow fever vaccine are required for Hajj pilgrims arriving from areas at risk of poliomyelitis and yellow fever transmission. Recommended vaccines include influenza, tetanus, pertussis, diphtheria, measles, and mumps.

Health Control Centers (HCCs) at 31 Points of entry (PoE) work under IHR to prevent disease importation ${ }^{15}$. Hajj pilgrims must meet specific health requirements to obtain a Hajj visa. To the best of our knowledge, no recent reports have been published to estimate the trend in vaccine coverage for meningitis, yellow fever, or polio vaccine. A detailed review of the vaccine adherence data among the pilgrims arriving for Hajj from around the globe can help identify vaccination trends. It can guide future policymaking to ensure the prevention of any outbreaks. This study aims to describe the adherence rate and other variables associated with compliance to vaccination requirements for meningococcal meningitis, yellow fever, and polio during the Hajj season for 2017-2019.

\section{MATERIALS AND METHODS}

We analyzed data using descriptive statistics for pilgrims and seasonal workers (Hajj travelers to represent the combined population) arriving in Saudi Arabia for Hajj from January 2017-December 2019. Data were collected by HCCs at PoE and entered into Saudi Arabia's Health Electronic Surveillance Network (HESN). Included subjects were Hajj travelers from targeted countries. We reviewed data on vaccines against meningococcal meningitis, poliomyelitis, or yellow fever in Hajj pilgrims. Umrah pilgrims (those performing rites outside of Hajj season) were excluded, with the Hajj season lasting for ten days each year.

The Institutional Review Board at the Saudi Center for Disease Control and Prevention reviewed and approved the study protocol. Data were collected 
retrospectively from HESN. No personally identifiable information was collected to protect participant's privacy. Data were stored on a password-protected computer.

We reviewed HESN data to collect information on total passengers arriving per country and the number of passengers vaccinated for meningococcal meningitis, poliomyelitis, and yellow fever. We performed a descriptive analysis of vaccination adherence rates. We conducted Chi-square tests to assess differences in compliance rate among pilgrims by year and country of origin.

\section{RESULTS AND DISCUSSION}

The number of pilgrimage-participating countries was 113 countries in 2017, 128 in 2018, and 132 in 2019. Figure 1 shows countries where Hajj pilgrims were received in KSA with yellow fever and polio risk in 2019. The gender distribution of Hajj pilgrims was almost the same for the three years.

\begin{tabular}{l|l}
\hline \multicolumn{2}{c}{ Legend } \\
\hline & Yellow fever and Polio \\
\hline & Yellow fever \\
\hline & Polio \\
\hline
\end{tabular}

Figure 1. Risk-based Color Coded GeoMap of Countries from where Hajj Pilgrims were Received in 2019.

Table 1. The total Hajjis and Adherence Rates for Meningitis, Yellow fever, and Polio Vaccination, 2017-2019.

\begin{tabular}{ccc}
\hline Year & $\begin{array}{c}\text { Total Hajjis } \\
\text { Received }\end{array}$ & Meningitis vaccine Adherence Rate \\
2017 & $1,723,192$ & $86 \%$ \\
2018 & $1,692,407$ & $89 \%$ \\
2019 & $1,691,699$ & $91 \%$ \\
All years & $5,107,298$ & $89 \%$ \\
Year & $\begin{array}{c}\text { Total Hajjis } \\
\text { Received }\end{array}$ & Yellow fever vaccine Adherence Rate \\
2017 & 184,424 & $94 \%$ \\
2018 & 172,606 & $88 \%$ \\
2019 & 181,965 & $84 \%$ \\
All years & 539,995 & $89 \%$ \\
Year & Total Hajjis & Polio vaccine Adherence Rate \\
& Received & $67 \%$ \\
2017 & 769,918 & $80 \%$ \\
2018 & 362,762 & $52 \%$ \\
2019 & 393,103 & $66 \%$ \\
All years & $1,525,783$ & \\
\hline
\end{tabular}


Table 1 shows the total number of Hajjis and the percentage that met vaccine requirements (vaccination adherence). Overall mean adherence to meningitis vaccination requirements was $90 \%$, overall mean adherence to yellow fever vaccination requirements was $81 \%$, and overall mean adherence to polio vaccination requirements was $66 \%$. Meningitis vaccine coverage increased by $5 \%$ over the observed time frame. The increase was not statistically significant when comparing the difference of mean adherence over time $(p=0.1)$. Yellow fever vaccination adherence decreased significantly $(p<0.01)$ by $10 \%$ from 2017-2019. Polio vaccination adherence decreased by 5\% between 2017-2019 ( $p=0.08)$.

Table 2. Adherence to Meningitis, Yellow fever and Polio Vaccination by Continent, 2017-2019.

\begin{tabular}{|c|c|c|c|c|c|c|c|c|}
\hline \multirow{10}{*}{ 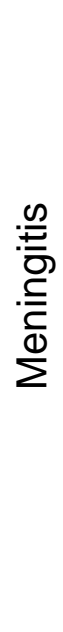 } & Continent & $\begin{array}{c}\text { Count } \\
\text { ries }\end{array}$ & $\begin{array}{c}\text { Adhe } \\
\text { rence } \\
(\%)\end{array}$ & $\begin{array}{l}\text { Coun } \\
\text { tries }\end{array}$ & $\begin{array}{c}\text { Adhe } \\
\text { rence } \\
(\%)\end{array}$ & $\begin{array}{l}\text { Coun } \\
\text { tries }\end{array}$ & $\begin{array}{c}\text { Adhe } \\
\text { rence } \\
(\%)\end{array}$ & Total (\%) \\
\hline & Africa & 44 & 89 & 48 & 94 & 49 & 92 & 92 \\
\hline & Asia & 39 & 81 & 42 & 82 & 38 & 86 & 83 \\
\hline & Europe & 21 & 88 & 25 & 88 & 31 & 91 & 90 \\
\hline & America & 5 & 88 & 9 & 100 & 11 & 100 & 98 \\
\hline & Australia & 4 & 100 & 4 & 100 & 3 & 100 & 100 \\
\hline & Total & 113 & 89 & 128 & 93 & 132 & 94 & 93 \\
\hline & $\begin{array}{c}\text { Africa's } \\
\text { Meningitis Belt }\end{array}$ & 15 & 98 & 15 & 89 & 16 & 94 & 94 \\
\hline & Others & 98 & 85 & 113 & 89 & 116 & 90 & 88 \\
\hline & Total & 113 & - & 128 & - & 132 & - & 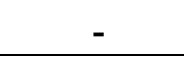 \\
\hline$\overline{-}$ & Africa & 21 & 94 & 12 & 88 & 22 & $85^{*}$ & 89 \\
\hline 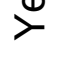 & The Americas & 0 & - & 0 & - & 3 & 72 & 72 \\
\hline 0 & Africa & 14 & 72 & 6 & 31 & 8 & $33^{*}$ & 52 \\
\hline$\Omega$ & Asia & 5 & 65 & 3 & 65 & 3 & $60^{*}$ & 63 \\
\hline
\end{tabular}

Table 2 shows Meningitis vaccination adherence by continent. The overall mean adherence to meningitis vaccination was $89 \%$ in $2017,93 \%$ in 2018 , and $94 \%$ in 2019. The number of countries where $<100 \%$ of all pilgrims were vaccinated for meningitis decreased in 2018 to 8 and 7 in 2019, with Asia having the lowest overall adherence rate (83\%). Nine countries had less than $80 \%$ meningitis vaccination adherence rate in 2017: Qatar (0\%), Yemen (2.1\%), Nepal (5\%), Afghanistan (46\%), Kazakhstan (53\%), Syria (62\%), and Palestine (72\%), Pakistan (73\%), and Myanmar (80\%). In 2018, 12 countries had less than $80 \%$ meningitis vaccination adherence. Yemen, Pakistan, Afghanistan had less than 40\%, Nepal, Ukraine, and Myanmar countries had between 40-65\%, and Iraq, Bangladesh, Cambodia, Jordan, and Palestine had between $65-80 \%$ of pilgrims vaccinated for meningitis. In 2019 , only six countries had less than $80 \%$ adherence, with Yemen and Afghanistan at an adherence rate of less than $45 \%$, Turkmenistan, Jordan, and Palestine between $60-70 \%$, and Pakistan at $79.6 \%$.

We compared Africa's meningitis belt countries to other countries for meningitis vaccine adherence (Table 3). Africa's meningitis belt includes Sudan, South Sudan, Mali, Burkina Faso, Guinea, Guinea-Bissau, Nigeria, Ethiopia, Cote d'Ivoire, Niger, Benin, Cameroon, Chad, Eritrea, Gambia, Senegal, Republic of Central Africa. The 
difference in adherence between meningitis belt countries and the others was significant for $2017(p<0.01)$, with the mean value of the Meningitis belt at $98 \%$ and others at $85 \%$.

Table 2 shows the yellow fever vaccine adherence in African and American Yellow Fever endemic countries. The overall trend in adherence has decreased significantly $(p<0.01)$. In 2018 , only $27 \%$ of the entire countries had $100 \%$ adherence rates. South Sudan and Burundi had less than 10\% adherence to Yellow Fever vaccination requirements, and the rest of Africa had more than $85 \%$ adherence. In 2019,6 out of 25 (24\%) countries had more than $80 \%$ of pilgrims vaccinated for Yellow Fever. Gabon, Panama, Chad, and Ghana had adherence between 25-65\%. Between 65-80\% of pilgrims from Chad, Kenya, Niger, Mauritania, and Mali were vaccinated for Yellow Fever.

Adherence to polio vaccine requirements decreased over time in Asian and African countries (Table 2). In 2017, Mali and Congo had an adherence rate of less than $70 \%$. In 2018, Mali, Niger, South Sudan, and Sudan had 0\% adherence, whereas Nigeria and Somalia had more than $90 \%$. In 2019, Congo, Guinea, and Mali had a 0\% adherence rate. Niger and Somalia had 30-60\%, and the remaining six countries had more than $80 \%$. Yemen had a $<1 \%$ adherence rate; Syria, Pakistan, and Iraq had $70-$ $90 \%$. Afghanistan had a $93 \%$ adherence rate. In 2018, Yemen had less than $2 \%$ adherence while Pakistan and Afghanistan had more than 95\%. In 2019 again, Yemen had $1 \%$ adherence, Afghanistan $85 \%$, and Pakistan $94 \%$. Overall, polio vaccine adherence in polio-endemic countries and polio-high-risk countries was found to be $66 \%$. The overall Polio vaccination adherence rate dropped from $67 \%$ to $52 \%$ from 2017-2019 for all Hajjis.

Table 3 provides the total number of pilgrims from counties from various belts: African belt, south Asian belt, Eat Asian Belt, Arab Belt, Turkish Belt, and US/Europe belt. It also presents the proportion of pilgrims from each country within each belt. Although the number of countries varied, the overall adherence to vaccination requirements did not vary significantly over three years.

As the number of participating countries and Hajj travelers continues to increase, so does the risk for outbreaks. Vaccination is a critical tool to preventing many outbreaks, and we found vaccine adherence rates much less than $100 \%$ and that vaccination rates varied significantly across regions. Analysis of these differences and the trends in adherence rates can guide stakeholders in policymaking to increase coverage and minimize the risk of outbreaks.

Mass immunization campaigns have led to a significant reduction in transmission of infections among pilgrims since 200116-19. High adherence rates among pilgrims from North America and Australia in our study are supported by the gradual decline in the incidence of bacterial meningitis in Western countries by 3-4\% per year to $0.7-0.9$ per 100,000 per year in the past $10-20$ years $^{20}$, likely due to mass immunization campaigns in the regions. The number of pilgrims not vaccinated for meningitis was high for Asia and Europe. Meningitis incidence rates are still higher among African countries (Burkina Faso and Malawi) (Table 2) ${ }^{20}$. Vaccine adherence for Africa's meningitis belt was higher than other African countries, as shown in Table 2. Meningitis vaccination adherence peaked in 2017 , then dropped significantly in 2018, and by 2019 had still not recovered (Table 1). According to WHO, routine meningitis immunization has been introduced in the African meningitis belt since 2016 . As of April 2021, 26 countries in the African meningitis belt have conducted mass preventive campaigns ${ }^{16}$. The uptick in adherence to meningitis vaccination may be due to these collaborative efforts between WHO and endemic countries. 
Yellow fever virus is endemic to the subtropical and tropical areas of Africa and South America. Yellow fever vaccine adherence decreased significantly during the study period. The adherence rates were higher among the American countries as compared to African countries (Table 2).

Table 3, Overall Vaccine Adherence Rate by Country and Year, 2017-2019

\begin{tabular}{|c|c|c|c|}
\hline \multirow[b]{2}{*}{ African Belt } & \multicolumn{3}{|c|}{$\%$ Vaccinated } \\
\hline & 2017 & 2018 & 2019 \\
\hline Ethiopia & 8 & 8 & 9 \\
\hline Eritrea & 0 & 0 & 0 \\
\hline Sudan & 20 & 21 & 20 \\
\hline Cameroon & 1 & 2 & - \\
\hline Niger & 7 & 7 & 7 \\
\hline Benin & 1 & 0 & 1 \\
\hline Burkina Faso & 4 & 5 & 4 \\
\hline Chad & 2 & 3 & 4 \\
\hline The Gambia & 1 & 1 & 1 \\
\hline Central Africa & 0 & 0 & 0 \\
\hline Guinea & 3 & 4 & 4 \\
\hline Guinea-Bissau & 0 & 0 & 0 \\
\hline Côte d'Ivoire & 3 & 4 & 4 \\
\hline Mali & 6 & 7 & 7 \\
\hline Nigeria & 45 & 32 & 33 \\
\hline Senegal & - & 7 & 6 \\
\hline $\begin{array}{c}\text { South Sudan } \\
\text { Belt Total }\end{array}$ & - & 0 & 0 \\
\hline Arab Belt & 2017 & 2018 & 2019 \\
\hline UAE & 3 & 1 & 1 \\
\hline Bahrain & 1 & 1 & 1 \\
\hline Algeria & 11 & 12 & 11 \\
\hline Libya & 3 & 3 & 4 \\
\hline Syria & 4 & 5 & 5 \\
\hline Somalia & 2 & 3 & 3 \\
\hline Iraq & 13 & 13 & 17 \\
\hline Kuwait & 3 & 2 & 1 \\
\hline Morocco & 11 & 11 & 12 \\
\hline Yemen & 7 & 8 & 8 \\
\hline Oman & 4 & 4 & 4 \\
\hline Palestine & 3 & 3 & 3 \\
\hline Qatar & 0 & 0 & 0 \\
\hline Lebanon & 5 & 4 & 3 \\
\hline Egypt & 3 & 29 & 29 \\
\hline Mauritania & 1 & 1 & 1 \\
\hline Belt Total & & & \\
\hline South African Belt & 2017 & 2018 & 2019 \\
\hline Uganda & 9 & 7 & 4 \\
\hline Togo & 22 & 20 & 15 \\
\hline Tanzania & 11 & 9 & 18 \\
\hline South Africa & 37 & 46 & 34 \\
\hline Djibouti & 21 & 18 & 29 \\
\hline
\end{tabular}




\begin{tabular}{|c|c|c|c|}
\hline \multicolumn{4}{|l|}{ Belt Total } \\
\hline South Asian Belt & 2017 & 2018 & 2019 \\
\hline India & 35 & 35 & 41 \\
\hline Pakistan & 39 & 38 & 38 \\
\hline Bangladesh & 25 & 25 & 20 \\
\hline Sri Lanka & 2 & 1 & 1 \\
\hline Nepal & 0 & 0 & 0 \\
\hline \multicolumn{4}{|l|}{ Belt Total } \\
\hline East Asian Belt & 2017 & 2018 & 2019 \\
\hline China & 4 & 4 & 5 \\
\hline Philippines & 2 & 3 & 3 \\
\hline Indonesia & 76 & 79 & 80 \\
\hline Burunai & 0 & 0 & - \\
\hline Thailand & 3 & 3 & 3 \\
\hline Korea & 0 & 0 & 0 \\
\hline Singapore & 0 & 1 & 1 \\
\hline Maldives & 0 & 0 & 0 \\
\hline Malaysia & 14 & 10 & 8 \\
\hline Burundi & - & 0 & - \\
\hline \multicolumn{4}{|l|}{ Belt Total } \\
\hline Turkish Belt & 2017 & 2018 & 2019 \\
\hline Afghanistan & 12 & 13 & 13 \\
\hline Uzbekistan & 3 & 3 & 3 \\
\hline Iran & 32 & 34 & 36 \\
\hline Azerbaijan & 1 & 0 & 1 \\
\hline Turkmenistan & 0 & 1 & 1 \\
\hline Turkey & 49 & 46 & 44 \\
\hline Dagestan & 0 & 0 & 0 \\
\hline Tajikistan & 2 & 3 & 2 \\
\hline Kazakhstan & 1 & 1 & 1 \\
\hline \multicolumn{4}{|l|}{ Belt Total } \\
\hline $\begin{array}{c}\text { Europe, United States } \\
\text { of America }\end{array}$ & 2017 & 2018 & 2019 \\
\hline Australia & 3 & 4 & 5 \\
\hline Bosnia & 4 & 2 & 4 \\
\hline Sweden & 0 & 0 & 0 \\
\hline UK & 20 & 21 & 15 \\
\hline Norway & 0 & 0 & 1 \\
\hline USA & 14 & 16 & 16 \\
\hline Greece & 1 & 0 & 0 \\
\hline Italy & 3 & 3 & 2 \\
\hline Spain & 1 & 1 & 2 \\
\hline Albania & 0 & 0 & 0 \\
\hline Germany & 3 & 3 & 2 \\
\hline Russia & 37 & 36 & 37 \\
\hline Switzerland & 1 & 0 & 1 \\
\hline France & 10 & 11 & 12 \\
\hline Canada & 4 & 3 & 3 \\
\hline Serbia & - & - & 1 \\
\hline Belt Total & & & \\
\hline
\end{tabular}


Our findings also suggest weaknesses in The Eliminate Yellow fever Epidemics (EYE) Strategy launched in 2017, as indicated by a reduction in the percentage of vaccinated individuals arriving from Yemen from 2017-2019 (Table 2) ${ }^{21}$. The partnership supports 40 at-risk countries in the Americas and Africa to prevent, detect, and respond to yellow fever suspected cases and outbreaks ${ }^{21}$. The global shortage of yellow fever vaccines in recent years, the difficulties of properly storing and transporting yellow fever vaccines, and the serious adverse effects associated with vaccines could increase the number of at-risk unvaccinated travelers, including Hajj pilgrims $^{22}$. IHR requires travelers to provide certificates for yellow fever vaccination; this requirement is inadequately monitored and enforced ${ }^{21}$. Vector control can prevent transmission, and the Saudi government must ensure appropriate vector control efforts to reduce exposure to pilgrims.

Poliomyelitis is a highly infectious disease that mainly affects children under the age of 5 years. In 1988, WHO adopted a resolution for polio eradication and launched the Global Polio Eradication Initiative ${ }^{23}$; wild poliovirus cases have decreased by over $99 \%$ since then. Wild poliovirus types 2 and 3 have been completely eradicated ${ }^{23}$. Wild poliovirus type 1 cases are still reported in Pakistan and Afghanistan ${ }^{23}$. Polio vaccine adherence decreased over the study period among pilgrims from Africa and Asia (Table 2). The decrease was observed for both pilgrims from countries with wild polio and vaccine-derived polio cases. Closer analysis showed that the proportion of countries with full adherence decreased to zero in 2019 (Table 2).

Similarly, the countries with $>90 \%$ coverage also reduced during the study period. Adherence rates were not satisfactory for polio vaccination among the endemic countries from Asia and Africa (Table 3). Afghanistan's ongoing conflict makes vaccination efforts difficult, and travelers from Afghanistan can bring polio to Pakistan. In Pakistan, the mass immunization campaigns are organized routinely by the joint efforts of the government, WHO, and UNICEF, trying to improve relations with marginalized ethnic and religious groups to enhance vaccine uptake. The reduced proportion of unvaccinated individuals from these countries indicates the success of these efforts among Hajj pilgrims.

Pilgrims' interaction starts long before they arrive in Saudi Arabia, and any vaccination provided upon arrival would not immediately provide immunity. The Saudi government provides one dose of oral polio vaccine (OPV) to all pilgrims who have not been vaccinated. While a single dose cannot provide complete immunity, the booster dose can increase immunity among adults who have been immunized during childhood $^{24}$. OPV also has the potential to infect others and cause symptomatic disease.

We conducted a retrospective study and collected data from an existing surveillance program. No individual data were collected to identify any factors that may impact vaccine compliance rates. Furthermore, our study focused on only three diseases. The respiratory viruses have been responsible for pandemics, and we are still facing one. These viruses spread more quickly and cause serious life-threatening illnesses. Respiratory diseases such as influenza and recently emerged severe acute respiratory syndrome-associated coronavirus 2 (SARS-CoV 2) must also be accounted for. The adherence rates for the vaccination against respiratory viruses must also be analyzed in the future to further decrease the risk of any outbreaks.

\section{CONCLUSION}

During Hajj, the risk of meningitis, yellow fever, and poliomyelitis is mainly preventable through maximizing vaccine coverage. While the adherence trend for the 
meningitis vaccine showed an increase, the reverse was observed for yellow fever and polio among Hajj pilgrims during 2017-2019. The government of the respective country must ensure compliance with vaccine requirements, and the government of KSA must only grant visas to those providing vaccine certificates. Future investigations should focus on respiratory diseases such as influenza and severe acute respiratory syndrome-associated coronavirus 2 (SARS-CoV 2). While vaccines are not as widely available, these viruses, on the other hand, spread globally and rapidly, causing severe life-threatening illnesses. Adherence rates for the vaccination against respiratory viruses must also be analyzed to further decrease the risk of any outbreaks. Currently, the vaccine against SARS-COV 2 is included in the list of required vaccines, and the influenza vaccine is only recommended for Hajj.

\section{ACKNOWLEDGMENTS}

Author Thank you to my supervisor, Dr. Joanna Gaines, for providing guidance and feedback throughout this project.

\section{CONFLICT OF INTERESTS}

There are no competing interests among study authors or funding sources.

\section{REFERENCES:}

1. World Health Organization. What are the International Health Regulations and Emergency Committees? 2019. https://www.who.int/news-room/q-a-detail/whatare-the-international-health-regulations-and-emergency-committees. Last accessed 2021-08-15.

2. Algarni $\mathrm{H}$, Memish ZA, Assiri AM. Health conditions for travelers to Saudi Arabia for the pilgrimage to Mecca (Hajj)-2015. Journal of epidemiology and global health 2016;6(1):7.

3. Alomi YA, Hakami LEA, Khayat NAY, et al. Mass Gathering (Hajj) Pharmacy Infection Control: New Initiative in Saudi Arabia. International Journal of Pharmacology and Clinical Sciences 2020;9(1)

4. Salmon-Rousseau A, Piednoir E, Cattoir V, et al. Hajj-associated infections. Med Mal Infect 2016;46(7):346-54. DOI: 10.1016/j.medmal.2016.04.002 [published Online First: 2016/05/28]

5. Shafi S, Booy R, Haworth E, et al. Hajj: health lessons for mass gatherings. J Infect Public Health 2008;1(1):27-32. DOI: 10.1016/j.jiph.2008.08.008 [published Online First: 2008/01/01]

6. Ahmed QA, Arabi YM, Memish ZA. Health risks at the Hajj. The Lancet 2006;367(9515):1008-15.

7. Al-Tawfiq JA, Gautret P, Benkouiten S, et al. Mass gatherings and the spread of respiratory infections. Lessons from the Hajj. Annals of the American Thoracic Society 2016;13(6):759-65.

8. Memish ZA, Zumla A, Alhakeem RF, et al. Hajj: infectious disease surveillance and control. The Lancet 2014;383(9934):2073-82.

9. World Health Organization. Health issues in the Hajj pilgrimage: A literature review. 2019. http://www.emro.who.int/emhj-volume-25-2019/volume-25-issue10/ health-issues-in-the-hajj-pilgrimage-a-literature-review.html. Last accessed 202108-15.

10. Dull PM, Abdelwahab J, Sacchi CT, et al. Neisseria meningitidis serogroup W-135 carriage among US travelers to the 2001 Hajj. J Infect Dis 2005;191(1):33-9. DOI: 10.1086/425927 [published Online First: 2004/12/14] 
11. Memish ZA, Al-Tawfiq JA, Almasri $M$, et al. Neisseria meningitides nasopharyngeal carriage during the Hajj: A cohort study evaluating the need for ciprofloxacin prophylaxis. Vaccine 2017;35(18):2473-78. DOI: 10.1016/j.vaccine.2017.03.027 [published Online First: 2017/03/28]

12. Balkhy $\mathrm{HH}$, Memish ZA, Osoba AO. Meningococcal carriage among local inhabitants during the pilgrimage 2000-2001. International journal of antimicrobial agents 2003;21(2):107-11.

13. Al-Tawfiq JA, Memish ZA. Prevention of pneumococcal infections during a mass gathering. Hum Vaccin Immunother 2016;12(2):326-30. DOI: 10.1080/21645515.2015.1058456 [published Online First: 2015/07/16]

14. Memish ZA, Assiri A, Turkestani A, et al. Mass gathering and globalization of respiratory pathogens during the 2013 Hajj. Clinical Microbiology and Infection 2015;21(6):571. e1-71. e8.

15. Salaheldin MH, Hassanain MA, Ibrahim AM. Systematic conduct of POE for polyclinic facilities in Saudi Arabia. Archnet-IJAR: International Journal of Architectural Research 2020

16. World Health Organization. Meningococcal meningitis. 2018. https://www.who.int/news-room/fact-sheets/detail/meningococcal-meningitis. Last accessed 2021-08-15.

17. Abd El Ghany M, Sharaf H, Hill-Cawthorne GA. Hajj vaccinations-facts, challenges, and hope. International Journal of Infectious Diseases 2016;47:29-37.

18. Badahdah A-M, Alghabban F, Falemban W, et al. Meningococcal vaccine for hajj pilgrims: Compliance, predictors, and barriers. Tropical medicine and infectious disease 2019;4(4):127.

19. Yezli S, Assiri AM, Al-Hakeem RF, et al. Meningococcal disease during the Hajj and Umrah mass gatherings. Int $J$ Infect Dis 2016;47:60-4. DOI: 10.1016/j.jij.2016.04.007 [published Online First: 2016/04/12]

20. Brouwer MC, van de Beek D. Epidemiology of community-acquired bacterial meningitis. Curr Opin Infect Dis 2018;31(1):78-84. DOI: 10.1097/qco.0000000000000417 [published Online First: 2017/11/28]

21. World Health Organization. Yellow fever. 2019. https://www.who.int/newsroom/fact-sheets/detail/yellow-fever. Last accessed 2021-08-15.

22. World Health Organization. Detection and investigation of serious adverse events following yellow fever vaccination, Geneva 2010.

23. World Health Organization. Poliomyelitis. 2021. https://www.who.int/healthtopics/poliomyelitis\#tab=tab_1. Last accessed 2021-08-15.

24. Center for Disease Control and Prevention. Polio Vaccination: What Everyone Should Know. 2017. https://www.cdc.gov/vaccines/vpd/polio/public/index.html. Last accessed 2021-08-15. 